\title{
Vida y propiedad privada: Una mirada sociológica sobre el funcionamiento del sistema penal argentino
} Martina Lassalle

Universidad de Buenos Aires, Buenos Aires, Argentina

\begin{abstract}
Vida e propriedade privada: Um olhar sociológico sobre o funcionamento do sistema penal argentino explora o modo como esse sistema penal estrutura a relação e as hierarquias entre dois valores supremos nas sociedades contemporâneas: a vida individual e a propriedade privada. Para isso, analisamos como são punidos os assassinatos e os atentados à propriedade privada. Primeiro, consideraremos as penalidades estabelecidas pelo código penal. Posteriormente, uma vez que há uma distância importante entre o que o direito codifica como proibido e o modo efetivo com que opera a agência judicial, analisaremos as condenações aplicadas para os assassinatos e os roubos.
\end{abstract}

Palavras-chave: vida individual, propriedade privada, assassinato, roubo, sistema penal argentino
Life and Private Property: A Sociological Inquiry about the Functioning of the Argentinean Criminal System explores the way in which this criminal system structures the relation and hierarchies between two main values in contemporary societies: individual life and private property. To this end, we analyze how murders and attacks against property are punished. Firstly, we will consider the penalties established in the penal code. Later, since there is an important distance between what written law prohibits and the effective way in which the judiciary operates, we will analyze and compare sentences for murder and for robbery.

Keywords: individual life, private property, murder, robbery, Argentinean criminal system

\section{Introducción}

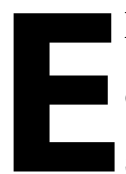

1 presente artículo se propone explorar el modo en que el sistema penal argentino estructura, mediante las prácticas de castigo, la relación y las jerarquías entre dos valores supremos en las sociedades contemporáneas: la vida individual y la propiedad privada. Para ello, analizaremos la manera en que se penalizan los homicidios y los atentados a la propiedad privada ${ }^{1}$.

Nos proponemos realizar nuestro análisis en dos niveles. En primer lugar, consideraremos las penas establecidas por el código penal. Una mirada atenta sobre la codificación, sobre el derecho "en abstracto", para utilizar la expresión de Baratta (2000), es ciertamente relevante pues el código jurídico funciona informando las prácticas del conjunto de los agentes judiciales. Las reacciones contra las posturas formalistas en torno a la ley, incluso por parte de la criminología, han conducido muchas veces a poner en segundo plano el estudio de la regla jurídica para otorgarle un lugar privilegiado - y casi exclusivo - al análisis de las prácticas de castigo efectivas. No obstante, tal como sugiere Bourdieu (2010), el efecto propio de la regla enunciada 
explícitamente, sobre todo cuando, como en el caso de la regla jurídica, está asociada a sanciones, no debiera ignorarse ni minimizarse pues la eficacia específica que ejerce el derecho como tal es particularmente imputable al trabajo de codificación, de puesta en forma y fórmula, de neutralización y de sistematización ${ }^{2}$. Asimismo, tratándose de un campo con jerarquías muy marcadas, no solo en relación a sus instancias y poderes sino también a las normas y fuentes que confieren autoridad a las decisiones de sus miembros (Ibid.), se comprenderá la importancia de analizar una norma suprema como el código penal.

Si aceptamos, como quiere Bourdieu (Ibid., p. 202), que el "derecho es la forma por excelencia del poder simbólico de nominación que crea las cosas nombradas", entonces resulta claro el lugar fundamental que la regla jurídica tiene en estos actos simbólicos de nominación. Nombrando una determinada conducta como homicidio, como robo o como estafa, el código jurídico no hace más que crearlas como tales. Ninguna de ellas preexiste a su nombramiento. Pero, al mismo tiempo que efectúa tales actos de nominación, también prohíbe ciertas conductas. $\mathrm{Y}$, al prohibirlas, el sistema penal no hace más rechazar ciertos valores y, como contrapartida, reafirmar otros (TONKONOFF, 2019a, 2019b). Así, donde el asesinato y los atentados a la propiedad privada están interdictos, el valor de la vida individual y de la propiedad privada se reafirman como hegemónicos. El código penal muestra precisamente la cristalización de esta lucha política por la definición de las acciones que tolerará una cultura, de las que tolerará un tanto menos, y las que rechazará por completo. Y no refiere a otra cosa más que a lo que la criminología crítica ha identificado como un primer momento de la selectividad penal o como procesos de criminalización primaria (BARATTA, 2000; PAVARINI, 2003; BERGALLI, 1996).

No obstante, si aceptamos que existe una distancia importante entre lo que el derecho codifica como prohibido y el modo efectivo en que opera la agencia judicial, entonces no basta con analizar los castigos prescriptos por el código jurídico para dar cuenta de las prácticas de castigo vigentes. Es preciso abordar también lo que Sutherland (1947) llamó "derecho en movimiento". Las prácticas de los jueces deben ajustarse, más o menos estrictamente, a las exigencias de la ley — de ahí la importancia de considerar seriamente el código jurídico —, pero siempre existe cierto margen de autonomía en sus decisiones, ya que "disponen del poder de explotar la polisemia o la anfibología de las fórmulas jurídicas" (BOURDIEU, 2010, p. 184). La interpretación y aplicación de una norma general, abstracta, a casos particulares está siempre atravesada por lógicas y conflictos de intereses propios del campo jurídico, a la vez que, por los sentidos sociales hegemónicos y las relaciones de género, poder y propiedad que configuran una determinada cultura.

Es por ello que, en segundo término, nos proponemos explorar y comparar las condenas efectivamente impuestas por los jueces para los homicidios intencionales y los robos. Solo 
trabajando en la intersección de las referencias más generales que constituyen el código jurídico y las prácticas de castigo efectivas podremos avanzar en una descripción más cabal del modo en que el sistema penal argentino ${ }^{3}$ configura la relación entre el valor de la vida y de la propiedad privada.

\section{La codificación jurídica}

La codificación jurídica es el resultado - siempre provisorio - de una lucha por la selección y definición de aquellas conductas que serán señaladas como delitos y, por consiguiente, de las que no lo serán. Como mencionáramos más arriba, se trata de "actos de nominación simbólica" (BOURDIEU, 2010) que muestran una disputa política por la definición de las conductas que una determinada cultura, en mayor o menor medida, aceptará, así como de las que rechazará por completo. No obstante, uno puede observar que el código no solo señala qué acciones serán prohibidas, sino que también las jerarquiza a través del establecimiento de penas específicas según la conducta de la que se trate. Esta jerarquización que es también parte de esa lucha política - se realiza en función de la gravedad que se le asigna a cada una de ellas. Y, así, ordenando los diferentes delitos mediante castigos de distinta duración, el código jerarquiza los bienes jurídicos que están en juego en las conductas que penaliza. Desde nuestra perspectiva, estos bienes jurídicos no son otra cosa más que valores ideológicos ${ }^{4}$ - la vida y la propiedad privada son dos de ellos - , y la jerarquización que el código produce responde tanto a la estructura ideológica de la sociedad en la que rige, como a las relaciones desiguales de género, poder y propiedad que la configuran.

Ahora bien, además de definir y jerarquizar las conductas prohibidas, el código también valora diferencialmente las formas que un mismo tipo de delito puede asumir. La escala que fija para cada tipo penal muestra el lugar que en esta valoración le corresponde a cada una de esas formas. De modo que la escala penal no es otra cosa que una escala de valoración. Los agravantes y los atenuantes definidos son operadores clave para llevar a cabo la valoración y penalización diferenciales de las distintas conductas que se encuentran prohibidas. Ambos son formas estrictamente valorativas; los primeros vuelven una determinada acción más grave, más severa, mientras que los segundos la vuelven más leve. Y resulta claro, entonces, que en el código jurídico abundan formas de valorar, de calificar (valorando) diversas acciones. Los adjetivos "grave" y "leve" se repiten a lo largo del mismo, en cada uno de los artículos, independientemente del delito del que se trate (homicidio, robo, delitos contra el honor, aborto etc.). 
Pero agreguemos que son las prácticas de castigo de jueces y fiscales las que ponen en movimiento de forma estratégica y selectiva esos operadores. $Y$, aunque el discurso jurídico no pueda reconocerlo y tienda a hablar de "circunstancias del caso", esta utilización está siempre vinculada a los sentidos sociales hegemónicos, así como a las relaciones de género, poder y propiedad que configuran una determinada sociedad.

Doble operación de valoración y penalización, entonces: por un lado, entre las distintas conductas prohibidas; por otro, entre las diferentes figuras que una misma conducta delictiva puede asumir. Si el código valora y pena diferencialmente las distintas formas que asumen los atentados a la vida y a la propiedad, ya no es pues suficiente afirmar, de manera general, que el sistema penal rechaza con mayor fuerza, y por tanto castiga más severamente, los homicidios que los robos, o incluso a la inversa. Es preciso prestar particular atención a esa segunda operación de valoración y penalización diferencial que mencionábamos; esto es, al modo en que se califican, se valoran y se penan las diferentes formas que los atentados a la vida y a la propiedad pueden asumir.

Pensemos pues la escala penal como un continuum penalen donde es posible ubicar diversas muertes intencionales y distintas clases de atentados a la propiedad según el tipo de castigo prescripto por el código. Así, mientras que en el extremo derecho encontramos la pena máxima (la reclusión perpetua) ${ }^{5}$, en el extremo izquierdo hallamos la ausencia de castigo, es decir, la inexistencia de delito. Y, a lo largo de todo el continuum, múltiples tipos de muertes intencionales y de atentados a la propiedad que, según la gravedad que el sistema penal considere que comportan, se ubicarán más hacia un extremo o hacia el otro. Una mirada sobre el lugar que ellos ocupan en este segmento nos permitirá comenzar a reconstruir, a partir del Código Penal argentino, la relación entre el valor de la vida individual y de la propiedad privada.

\section{La muerte violenta en sus diversas formas}

De manera general, parecería haber cierto consenso de que la vida individual ocupa el lugar más alto en la escala valorativa del sistema penal y que, por tanto, no habría peor acto que el de dar muerte a un individuo. En línea con ello, tenderíamos a pensar, entonces, que los castigos más severos están prescriptos en estos casos. Una primera mirada nos permite en parte efectivamente verificar esta hipótesis: el código jurídico dispone las penas más altas para los atentados contra las personas, y particularmente para los atentados contra la vida ${ }^{6}$. Así, vemos que un homicidio doloso - es decir, intencional - puede castigarse con entre ocho y 25 años de prisión; un máximo con el que ciertamente se penan pocos delitos. Podrá notarse que se trata de un espectro de penas bastante amplio y que no todas las muertes intencionales merecen, según el código, los castigos 
más elevados de esa escala. Son únicamente las figuras del homicidio agravado, y la de secuestro extorsivo seguido de muerte (intencional o no), aquellas para las cuales se estipulan castigos que superan los 16 años de prisión (la mitad en la escala penal fijada).

En el caso de los homicidios agravados, las penas son las más altas posibles: la reclusión perpetua. Pero ¿cuándo un homicidio se convierte en agravado? ¿Con qué tiene que combinarse esa muerte intencional para volverse una muerte digna de un castigo tan severo como una condena perpetua? Un vínculo cercano (familiar) entre víctima y victimario, el hecho de que la acción se consume con alevosía, por odio racial o religioso, o para ocultar o facilitar la consumación de otro delito como un robo (denominado criminis causae) - todas estas circunstancias hacen que estos homicidios sean, para el sistema penal, cualitativamente diferentes a cualquier otro. Y de ahí que merezcan ser penados de la forma más severa posible.

En el año 2012, a través de la ley no 26.791 , se produjo una modificación importante en el código penal pues se ampliaron los agravantes del homicidio. Por un lado, se estableció que el asesinato de una pareja, o expareja, haya habido o no convivencia, merece una pena perpetua tanto como el asesinato de la esposa o el marido (legalmente casados). Pero, además, se agregó un agravante específico, que antes no existía en ese artículo del código, y que establece que los asesinatos de mujeres en un contexto de violencia de género también recibirán las condenas máximas ${ }^{7}$

Estas incorporaciones fueron producto de muchos años de lucha política por parte del movimiento de mujeres, de su ascenso como un actor fundamental en la esfera pública en las últimas décadas y, con ello, de una fuerte propagación en el campo social de un conjunto amplio de creencias no patriarcales en torno a la mujer. En particular, las transformaciones que se observan en el código remiten a un intento por revalorizar la vida de la mujer en el seno de la pareja o, lo que es lo mismo, por mostrar que la muerte de una mujer en manos de su pareja es un acto altamente criminal, probablemente de los peores que existan. Al rol clave que asume el movimiento de mujeres - en su heterogeneidad - hemos de agregar otros actores sociales extrajurídicos, como organizaciones sociales, ciertos partidos políticos, algunos medios de comunicación, que también participan de esta lucha por volver hegemónicas este conjunto de creencias colectivas. La incorporación de estos agravantes en el código es pues la cristalización del ensamblaje penal que se articuló entre estos diversos actores sociales - incluidos los legisladores y los operadores judiciales - y que se orienta a la criminalización y repudio colectivo de la violencia de género y, por lo mismo, a un intento por revalorizar la desvalorizada vida de la mujer en el seno de la pareja patriarcal.

A todo lo anterior debemos sumar la figura del secuestro extorsivo agravado seguido de muerte - aunque en el código no figure como atentado a la vida, sino a la propiedad (artículo 170 de dicha ley) —, delito para el cual también se prescriben penas de prisión perpetua. De esta 
forma, si volvemos a preguntarnos con qué debe combinarse una muerte producida intencionalmente para que el código tenga esa acción como una acción merecedora de una pena tan severa como la prisión perpetua, diremos ahora: con un atentado a la propiedad privada y a la libertad. Tal vez se podría suponer - y de hecho es lo que el discurso jurídico sostiene - que es en realidad el atentado a la libertad de un individuo lo que hace que esa acción merezca el máximo castigo. No obstante, si atendemos a las penas establecidas para la privación ilegal de la libertad vemos que estas se ubican entre los dos y seis años.

Ahora bien, si esa privación ilegal de la libertad es perpetrada con el fin de cometer un atentado contra la propiedad privada (cobrar un rescate, por ejemplo), vemos una gran suba en los castigos establecidos: el mínimo pasa a ser de cinco u ocho años - en caso de que el autor logre apropiarse de la propiedad que se encontraba en juego - y el máximo de 15 años de prisión. Se podrá observar que, la privación ilegal de la libertad (sin muerte) se ve fuertemente agravada por el atentado a la propiedad privada - y la denominación que le corresponde en el código es la de secuestro extorsivo. Desde nuestra perspectiva, esto permite relativizar en gran medida lo que sostiene el discurso jurídico mismo de que sería fundamentalmente la combinación con el atentado a la libertad lo que explicaría que la muerte que le sigue al secuestro extorsivo se convierta en una muerte merecedora de una pena tan elevada. El ataque a la propiedad privada juega, según creemos, un rol decisivo en este agravamiento.

De manera que en el extremo derecho de nuestro continuum penal hemos de ubicar tanto los homicidios agravados como los secuestros extorsivos seguidos de una muerte perpetrada intencionalmente. Podríamos decir que, mediante el establecimiento de las penas más altas, el sistema penal parecería orientarse en una fuerte defensa del valor de la vida. Y tal vez sería más correcto afirmar que, mediante el establecimiento de estos castigos para ciertos homicidios, se orienta en una fuerte defensa de ciertas vidas. $Y$ es que en estas muertes hay también otros valores y sentidos sociales en juego. Son los vínculos familiares, el ser mujer de la víctima, el ataque a la libertad y a la propiedad privada en combinación con el atentado a la vida los que hacen que estas muertes sean consideradas realmente atroces y, por eso, jurídicamente rechazadas.

Mediante las penas que fija el código, el sistema penal muestra y "comunica socialmente" (GARLAND, 1999) que un femicidio, que el homicidio de un familiar, o un homicidio producido en el contexto de un secuestro extorsivo no son cualquier tipo de muerte. Son quizás muertes igualmente criminales entre sí pero, a la vez, las más criminales en comparación con todo el resto. Trataremos de explorar esto último en lo que sigue, pero ya aquí puede verse que, detrás de la afirmación (jurídica y del sentido común) de que la vida de todos vale y se protege por igual, lo cierto es que penalizando diferencialmente el sistema penal califica y clasifica las vidas de 
diferentes modos, y muestra que no todas tienen el mismo valor. Como veremos, matar a un familiar y matar a un desconocido en medio de una riña es cualitativamente diferente.

Un lugar muy cercano a este punto extremo del continuum penal le corresponde al secuestro extorsivo agravado seguido de una muerte culposa - no intencional - y al homicidio en ocasión de robo (en realidad llamado robo seguido de muerte), figuras para las cuales el código fija penas que van hasta el máximo establecido para el homicidio: 25 años de prisión. Resulta llamativo que en estos dos casos no se trata de muertes producidas intencionalmente y que así todo sean penalizadas con gran severidad: en el caso del secuestro es definitivamente no intencional, y en el caso del robo puede serlo pues la figura de robo seguido de muerte contempla tanto muertes intencionales como no intencionales ${ }^{8}$. De modo que dos muertes no intencionales quedan situadas en un punto muy cercano al extremo derecho de nuestro continuum (el máximo de pena). Si bien aquí no hemos de hacer referencia a otras posibles muertes culposas, lo cierto es que, de tener que ubicar estas últimas en el segmento propuesto, habríamos de ponerlas más bien cercanas al extremo izquierdo (ausencia de castigo). Y esto por cuanto el discurso jurídico sostiene que la "intención" de quien transgrede una prohibición es un elemento clave al momento de juzgar esa transgresión.

Pero entonces, ¿qué tienen de particular el secuestro seguido de muerte culposa y el robo seguido de muerte - incluso cuando esta no haya sido intencionalmente producida? Ambos están codificados como atentados a la propiedad, pero muestran la conjunción entre este último y un ataque a la vida. Y, en realidad, habría que decir que, en términos lógicos y temporales, son primero atentados a la propiedad, y luego atentados a la vida. Y también habría que volver a subrayar que tienen, por un lado, penas muy similares a aquellos homicidios intencionales que el código jurídico define como los más atroces de todos. De modo que una muerte no intencional en medio de un robo sería casi tan grave y criminal como un parricidio.

Pero, por otro lado, y como veremos en lo que sigue, estas penas son muy superiores a las de muchos otros homicidios producidos intencionalmente. Desde nuestra perspectiva, y aun cuando el discurso jurídico no pueda reconocerlo y sostenga lo contrario, la intención (o la no intención) de quien transgrede la prohibición de matar se encuentra en un segundo plano, y lo que verdaderamente toma protagonismo es que las muertes que el sistema penal se propone castigar de este modo representan un ataque a dos valores ideológicos primeros en las sociedades contemporáneas: la vida individual y la propiedad privada. De ahí que, como veníamos ya observando, la combinación de un atentado a la vida y a la propiedad privada transformen esa muerte en una muerte digna de las penas más altas posibles, aun cuando no haya sido producida intencionalmente. 
Se vuelve sin embargo evidente que existe una multiplicidad de otras muertes violentas posibles que no son leídas por el sistema penal a la manera de las anteriores; que, aun tratándose de transgresiones a la prohibición de matar, son tenidas como cualitativamente diferentes, son valoradas de otro modo. De ahí que el código jurídico establezca para ellas penas menores. Vale mencionar aquí los homicidios sin agravantes, aquellos ocurridos en riña, bajo emoción violenta, y los denominados preterintencionales ${ }^{9}$. Todos estos se localizan de la mitad de nuestro continuum hacia el extremo izquierdo del mismo.

En el caso del homicidio simple ${ }^{10}$, si bien la escala general es de ocho a 25 años, lo cierto es que, de no tener agravantes, las penas se ubican entre ocho y 15 años de prisión. Por su parte, para los homicidios ocurrido en riña se establecen castigos de entre dos y seis años de prisión, pudiendo ascender hasta casi ocho años si hubiera utilización de un arma de fuego. Además, es importante mencionar que, dado que son penas no perpetuas, los condenados podrían obtener libertad condicional una vez cumplidos los dos tercios del monto establecido. De este modo, un acusado por homicidio simple que hubiera sido sentenciado a 12 años de prisión podría alcanzar la libertad condicional a los ocho años.

Lo mismo podríamos decir de los condenados por homicidio en riña quienes, de haber obtenido la pena máxima (seis años), podrían quedar en libertad a los cuatro años. Claro que el análisis de las condenas efectivamente establecidas por los jueces resulta indispensable para evaluar lo anterior, pero es ciertamente relevante remarcar que ya el código mismo introduce estas posibilidades, lo cual hace visible que existen amplias diferencias entre estas penas y aquellas que, como vimos antes, se prescriben para las muertes intencionales agravadas o para una muerte en ocasión de robo. Así, como ya sugerimos anteriormente, dos atentados directos e intencionales a la vida, como un homicidio en riña o uno producto de un conflicto interpersonal, son, en la gramática del código jurídico, atentados menos graves, con un menor grado de criminalidad tal vez, que una muerte seguida de un atentado a la propiedad privada, aun cuando quien cometa ese ataque a la propiedad no haya buscado la muerte de la víctima.

De manera que, hasta aquí, esa primera mirada general que nos permitía sostener que el homicidio es en todos los casos la conducta más jurídicamente rechazada, comienza a ser un tanto problemática, e indudablemente debiera ser matizada. Y esto por cuanto hemos podido observar que las penalizaciones diferenciales que establece la codificación jurídica, y que por supuesto solo existen en las prácticas de los jueces y los fiscales, muestran que no todas las muertes son igualmente criminales. Para algunas, los castigos rondan los 20 o 25 años de prisión o la reclusión perpetua; para otras, las penas alcanzan, como máximo, los 15 años de prisión, pero los mínimos establecidos por el código permiten que los jueces puedan fijar castigos incluso menores a los tres años de encierro. 
Antes de pasar a analizar los castigos establecidos para los atentados a la propiedad, resta considerar una figura más que introduce el código. Se trata de la figura de la legítima defensa, la cual transforma ciertos asesinatos en no criminales. ¿En qué condiciones puede esto ocurrir según el código penal? Desde la lógica jurídica, alguien actúa en legítima defensa cuando se defiende a sí mismo, o sus derechos, siempre que haya habido una agresión ilegítima, que exista necesidad racional del medio empleado para impedirla o repelerla, y que no haya habido una provocación suficiente por parte de quien se defiende ${ }^{11}$. Si volvemos sobre el continuum penal propuesto más arriba, una muerte causada por un accionar en defensa propia debería ser ubicada exactamente en el extremo izquierdo, allí donde habíamos señalado la ausencia de castigo. Según vemos en este artículo del código, no solo una muerte intencional producida en defensa de la integridad física podría ser considerada como una acción en legítima defensa; de igual modo se considera una muerte provocada en defensa de un derecho propio, como el derecho de propiedad individual. La condición de la necesidad racional del medio empleado para impedir o repeler la agresión introduce cierto matiz que señalaría que, en teoría, no estaría permitido matar a quien intentase robar un objeto de valor personal, por ejemplo. No obstante, es una condición indudablemente ambigua: ¿cómo medir la necesidad racional del medio empleado para impedir la agresión? ¿Qué ocurre si la única forma que tiene un individuo de que no roben su vehículo es disparando un arma de fuego contra quien lo intenta, o arroyándolo con ese mismo vehículo? Es innegable que aquí se está defendiendo un derecho individual, y es probable que esa sea efectivamente la única forma de impedir que sea vulnerado. Pero entonces, ¿qué tiene más relevancia para el sistema penal: la defensa del derecho ofendido o el medio empleado para repeler la agresión?

Si bien la respuesta sociológica a este interrogante solo puede hallarse en la práctica efectiva de los jueces y fiscales (y no en los extensos debates de doctrina donde se la pretende encontrar), ${ }^{12}$ creemos que la misma no puede estar sino vinculada al valor ideológico que la agresión inicial vulnera. Es decir que solo un ataque que represente el atentado a un valor que ocupa un lugar privilegiado en la escala valorativa del sistema penal podría hacer primar, en la decisión de los jueces, la defensa del derecho atacado por sobre la necesidad racional del medio empleado. Desde nuestra óptica, ello explicaría que una muerte producida intencionalmente para repeler - aunque sea de forma excesiva - una agresión pueda ser leída como "legítima defensa" y no como un homicidio: matar intencionalmente a alguien actuando bajo la legítima defensa no es, según la gramática del código, un delito.

En este sentido, si vemos que esta figura del código admite también la defensa de la propiedad privada es porque evidentemente su ataque representa la vulneración de un valor ideológico ciertamente hegemónico. Y es esta vulneración la que hace que, paradójicamente, se pueda matar (atacando así otro valor ideológico supremo) sin que eso sea considerado criminal. Nuevamente, 
creemos que aquí puede verse con claridad la "altura del valor" propiedad privada, para usar una expresión de Frondizi (2010), en la escala de valores del sistema penal argentino.

De modo que a las diferentes muertes que antes analizamos debemos ahora agregar aquellas producidas en legítima defensa. A estas les corresponde un lugar de excepción, entendiendo esta última, no como un suceso fuera de lo común, sino como una salvedad a la regla. Toda conducta que termine con la vida de una o varias personas es nominada por el código penal como homicidio, y prohibida al ser señalada como un delito - como vimos, esta es la cristalización de una lucha política que se libra en el seno de los procesos de criminalización primaria. Al mismo tiempo, el código sostiene que terminar con la vida de una o varias personas para defender la vida u otro derecho propio no es un homicidio, sino una acción en legítima defensa. Si matar está prohibido, y esa es la regla general, matar en legítima defensa está permitido, y tal es la excepción a esa regla. Y es por eso que el lugar que le corresponde en nuestro contimuum penal a estas muertes, que bien podríamos calificar como no criminales, es precisamente el extremo izquierdo, la ausencia de castigo.

\section{Los atentados contra la propiedad}

El análisis de los castigos que el código prescribe para el homicidio intencional da cuenta de que no todos los homicidios son calificados y penados del mismo modo, lo cual, como vimos, complejiza la afirmación general según la cual el homicidio es el delito que recibe las penas más severas por ser un atentado a un valor ideológico que sería, en principio, el más importante de todos. Junto con lo anterior, hemos visto también el lugar privilegiado que tiene la propiedad privada: atendiendo al código, robar y matar es una conducta de extrema gravedad, pero matar para defender la propiedad individual puede no ser siquiera un delito. Asimismo, matar de manera no intencional cuando se intenta cometer un robo parece ser tan criminal como matar intencionalmente al propio esposo, o a un hermano.

Para seguir complejizando el análisis de la relación entre estos dos valores, exploremos ahora las penas que el código prescribe para los atentados a la propiedad. El hurto es el atentado a la propiedad con penas más leves: los castigos van desde un mes a dos años de prisión, aunque, si hubiera agravantes ${ }^{13}$, las penas se elevan, y el máximo pasa a ubicarse en seis años de prisión. Una escala similar a la de los hurtos agravados es la que se prescribe para el robo sin agravantes ${ }^{14}$. A su vez, también hay robos para los que las penas son un tanto más altas, alcanzando un máximo de 10 años de prisión. Se trata de robos en lugares despoblados, o en lugares poblados cuando estos se cometieran en grupos de tres o más personas, y de robos de maquinarias, o de un vehículo. Entonces, si volvemos sobre nuestro continuum penal, hemos de ubicar los hurtos en un lugar muy cercano al extremo izquierdo, y el robo simple (sin agravantes) un poco más hacia la mitad 
del segmento - en el lugar donde habíamos colocado el homicidio en riña. Así, a juzgar por los castigos estipulados por el código jurídico, una muerte producida de manera intencional por dos o más personas en una pelea comportaría la misma gravedad que un robo sin agravantes. En un caso, un atentado a la vida, en el otro un atentado a la propiedad.

Ahora bien, si el robo estuviera agravado por lesiones, o si fuera cometido con armas, o por un grupo de tres o más personas en un lugar despoblado, el mínimo establecido pasa a ser de cinco años, y su máximo de 15 años de prisión. Así, en nuestro segmento, esta figura se ubicaría entre los homicidios en riña, si fuera penado con el mínimo, y los homicidios simples, si fuera castigado con penas cercanas al máximo. Por otra parte, si en el robo agravado se utilizara un arma de fuego, tanto el máximo como el mínimo aumentan un tercio, por lo que la pena podría llegar casi a los 20 años de prisión ${ }^{15}$, ubicándose, de ese modo, en un punto cercano al extremo derecho del continuum penalpropuesto, y superando los castigos establecidos para el homicidio sin agravantes.

Este incremento en la pena que establece el código si existe uso de armas de fuego en los casos de robo fue producto de una modificación realizada en el año 2004 luego de un proceso de reforma legislativa en materia penal que se desencadenó a partir del secuestro y asesinato de Axel Blumberg, y de las masivas manifestaciones para pedir seguridad que este acontecimiento suscitó ${ }^{16}$. Los familiares y amigos de Axel, y fundamentalmente su padre, emprendieron "una cruzada moral" (BECKER, 2012), con mucho éxito por cierto, que dio lugar a un endurecimiento de la legislación penal argentina. La modificación de los mínimos y los máximos al tratarse de robos con arma de fuego es un ejemplo de ello, pero también se sancionaron otras leyes vinculadas a la forma de computar las penas y a la ejecución penal ${ }^{17}$. Cabe remarcar que este endurecimiento se dio particularmente en relación a determinados delitos que eran considerados especialmente graves: por ejemplo, el robo con armas, el robo en lugares despoblados, los delitos contra la integridad sexual seguidos de muerte, y los homicidios criminis causaesi se trata de un robo, aunque para este último delito no se modificó la escala penal pues el código ya establecía una perpetua. La efervecencia colectiva que desencadenó la muerte del joven Blumberg, y que ensambló a sus familiares, con los medios de comunicación, con vecinos, la clase política y, como vemos, también con el poder legislativo, paradójicamente no condujo a reformas penales que produjeran cambios en las escalas ni para la extorsión ni para el secuestro extorsivo - cuyo máximo es de 15 años, como veremos a continuación. Tampoco se modificó la escala del homicidio, ni se redujeron beneficios de excarcelación cuando el homicidio no fuera cometido con un robo.

En este sentido, los reclamos por seguridad - y los posteriores cambios legislativos - no parecieron tener en su horizonte "el delito violento" en general, sino solo algunos de ellos, vinculados fundamentalmente a los robos. El dispositivo penal, que articuló diversos actores sociales con actores judiciales y legislativos, y que se puso en movimiento a partir de este 
acontecimiento, parece entonces haber reafirmado fundamentalmente la criminalización de un tipo de atentado a la propiedad (el robo) y, con ello, la protección de la propiedad privada más que de la vida. Como señalamos antes, no hubo cambios en relación al delito de homicidio, salvo cuando estos ocurrieran en casos de robo.

Por último, nos queda mencionar el robo seguido de muerte - ya mencionado en el apartado más arriba -, para el cual se establecen castigos de hasta 25 años de prisión. Como vimos, esta figura ha de ser ubicada en un punto aún más cercano al extremo derecho, allí donde localizamos aquellos homicidios que el código presentaría como los más criminales y atroces de todos.

A los atentados a la propiedad antes señalados, hemos de agregar ahora la figura de la extorsión, y la de secuestro extorsivo, de la cual ya algo hemos mencionado. En nuestro continuum penal, la primera de ellas debiera situarse junto con el robo no agravado, levemente hacia la izquierda del punto medio. Por su parte, el secuestro extorsivo, ataque a la propiedad así como a la libertad, podría ser castigado con penas similares a las del robo agravado, penas que pueden alcanzar los 15 años de prisión - si volvemos a nuestro segmento, habríamos de ubicarlo hacia el medio del mismo. En el caso de que el secuestro extorsivo tenga agravantes, las penas prescriptas por el código jurídico son mayores y pueden ir de los 10 a los 25 años de encierro. De modo que su ubicación en nuestro continuum es muy cercana al extremo de la derecha, justo donde ubicamos el robo seguido de muerte. Cabe destacar que un secuestro extorsivo agravado no es necesariamente uno seguido de muerte. En este sentido, y a juzgar por los máximos establecidos, secuestrar una mujer embarazada o a un familiar con el fin de pedir un rescate - es decir, de atacar la propiedad individual -, es, en la gramática del código, tan grave como secuestrar a un desconocido que termine muriendo de un paro cardíaco. Finalmente, ubiquemos exactamente en el extremo derecho la figura de secuestro extorsivo seguido de muerte dolosa pues, como vimos, el código prescribe condenas perpetuas en estos casos.

Se notará que, al igual que en el caso de los homicidios, los atentados a la propiedad pueden castigarse con un amplio espectro de penas, incluso cuando no haya una muerte de por medio. Desde un hurto a un secuestro extorsivo agravado sin muerte, por ejemplo, las penas pueden oscilar entre el mes y los 25 años de reclusión.

Por último, resta introducir el delito de estafa y defraudación. El código prescribe entre un mes y seis años en estos casos, y si esta última es agravada (por estafa a seguros, por uso de medidas falsas, en perjurio de la administración pública etc.), entonces el mínimo en la escala pasa a ubicarse en los dos años. De este modo, puede verse que este tipo de delito es comparable con el hurto en su forma agravada, y con el robo, en su forma simple. Sin embargo, el robo de un vehículo en la vía pública, o en un lugar despoblado, son ya delitos más graves que la estafa. Y esto a pesar de que una estafa puede representar un atentado a la propiedad más significativo en términos económicos. 
Una explicación de lo anterior podría ser la inexistencia del ejercicio de la violencia física en una estafa, a diferencia de en un robo, por ejemplo. Tal explicación permitiría también aclarar por qué las penas prescriptas para el hurto son más bajas que para el robo. Es, además, una explicación que cualquiera de nosotros tendería a aceptar - y con la que probablemente estaríamos de acuerdo - pues toda acción en la que interviene el ejercicio de la violencia física es frecuentemente más repudiada, por considerarse de una gravedad mayor, que una en la que esta no intervenga, sobre todo si esa violencia se ejerce sobre una o varias personas. Tal argumento puede parecer convincente para los ejemplos anteriores, pero, ¿cómo explicar que una muerte producida intencionalmente (un homicidio en riña, por ejemplo) pueda ser menos grave que un robo donde no haya agresión hacia una persona (el robo de un vehículo, por ejemplo)? Es claro que en cualquiera de los casos donde haya muerte, la violencia física ejercida es, por así decirlo, llevada al extremo, por lo que esa acción sería sin duda más violenta. Pero, paradójicamente, el código prescribe castigos más altos para ciertos robos que para un homicidio en riña o, incluso, para algunos homicidios sin agravantes. ¿Cómo explicar esto entonces?

Evidentemente, la fórmula que habita el sentido común según la cual mayor violencia física, mayor gravedad y rechazo jurídico no parecería estar siempre vigente para el código penal argentino. Antes bien, lo que creemos que aquí puede verse con claridad, ya a nivel del derecho abstracto, es el componente clasista del sistema penal. En las prácticas de castigo, la clase social opera como un "diferencial" a partir del cual se administran selectivamente los ilegalismos (FOUCAULT, 2002, p. 277). Son los ilegalismos de las clases populares aquellos que el sistema penal perseguirá con mayor constancia y castigará de forma más severa. Desde nuestra perspectiva, antes que la frecuentemente proclamada existencia del ejercicio de la violencia física, es esta selectividad en las prácticas penales, que muestra distintos límites de tolerancia entre las diferentes clases, lo que explica que los robos - mayormente cometidos por clases bajas - tengan castigos mucho más altos que las estafas - mayormente cometidas por sectores medios y altos. La ley penal contribuye, en este sentido, a delimitar quiénes serán los sujetos propiamente criminales - los cometen robos, y no estafas - en una determinada sociedad. Siguiendo a Misse $(1999,2010)$, podríamos afirmar que, mediante estas diferenciaciones y jerarquizaciones, la ley penal participa de la interpelación de ciertos tipos sociales como criminales, interpelación de la cual también son parte otros agentes del sistema penal - como la policía y los operadores judiciales -, así como la opinión pública. 
Figura 1: Distribución del homicidio intencional y de los delitos contra la propiedad según la escala penal establecida por el código penal argentino

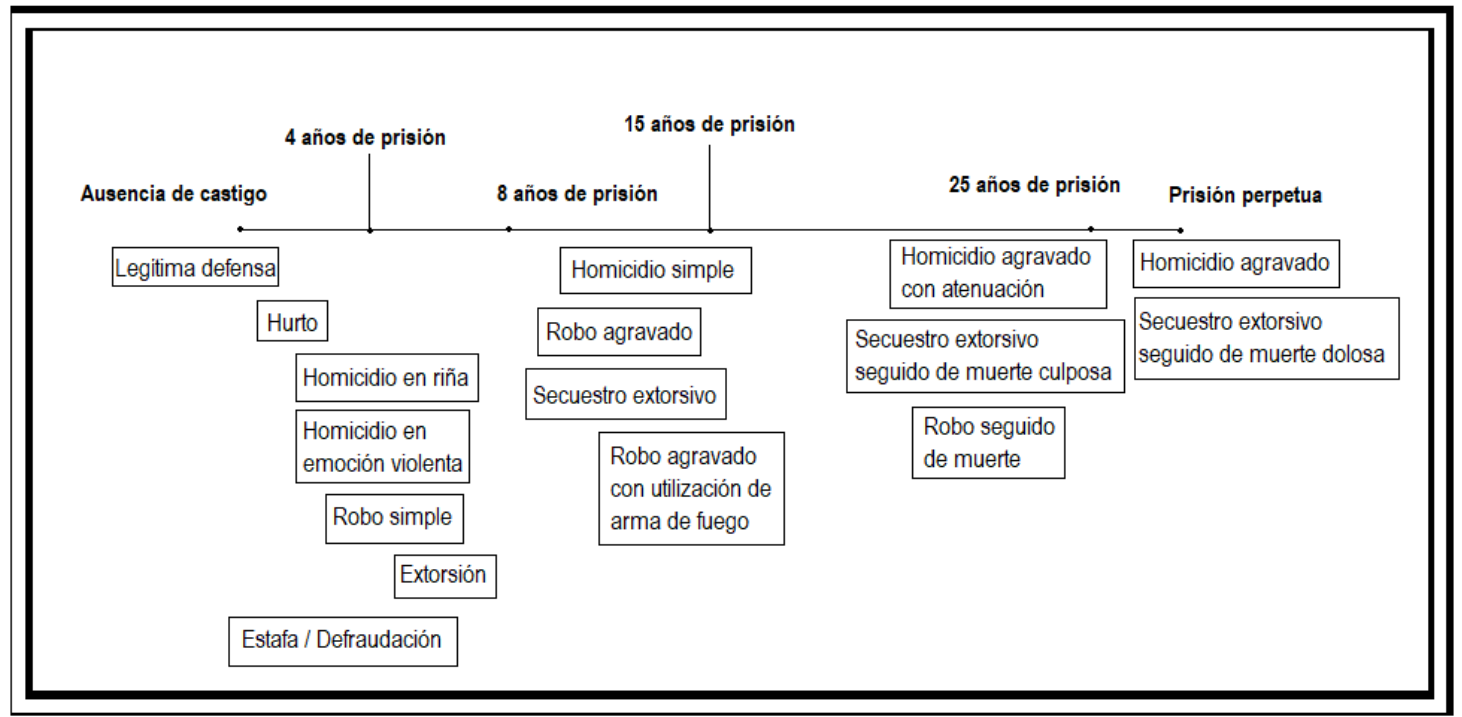

Fonte: Elaboración propia.

\section{Prácticas de castigo efectivas: asesinato y robo}

Las penas que prescribe el código jurídico para los atentados contra la vida y contra la propiedad, en sus diferentes figuras, dejan ver que no siempre los primeros tienen castigos más altos que los segundos. Antes bien, la jerarquía de valores que se puede reconstruir a partir del código no permite observar con claridad que exista superioridad absoluta del valor de la vida por sobre el de la propiedad privada. Y es que hay atentados a la propiedad (como el robo agravado, por ejemplo) que, en la práctica, pueden ser punidos con mayor severidad que ciertas muertes violentas (un homicidio en riña o un homicidio sin agravantes, por ejemplo). Afirmamos que "pueden" ser castigados de este modo, ya que, aun cuando el código dé lugar a ello, lo cierto es que existe una importante distancia entre lo que este prescribe y las prácticas concretas de las agencias penales.

Como ha remarcado Bourdieu (2010, p. 183) en sus análisis sobre el campo jurídico, si bien existen reglas escritas que tienden a reducir la variabilidad de los comportamientos de los jueces, ellos no son nunca meros ejecutantes que deducen de la ley conclusiones directamente aplicables a un caso particular. Y esto, puesto que la ley es abstracta, general, y el caso siempre concreto (CARNELUTTI, 2016). Es decir, lo que en el código aparece como un homicidio simple, al juez se le presenta como un hecho con una dimensión espaciotemporal específica entre dos (o más) personas que tienen edad y género, que pertenecen a determinados estratos socioeconómicos y no a otros etc. Y agreguemos que todo esto ocurre en sociedades socio-históricamente situadas, 
por lo que las prácticas de castigo están siempre atravesadas por una configuración ideológica específica y por relaciones desiguales de género, poder y de propiedad.

En la práctica podría ocurrir que los jueces castigaran los atentados a la propiedad con penas cercanas al mínimo, y los atentados a la vida con penas cercanas al máximo en la escala. Y, si así sucediera, verificaríamos que la modulación efectiva del castigo contribuiría a ubicar el valor de la vida por sobre el de la propiedad privada, incluso cuando el código habilitara, en parte, a que lo contrario ocurriese. De modo que es necesario analizar las penas impuestas para los delitos de homicidio y de robo a fin de poder examinar lo anterior; es decir, para poder complementar lo que hemos observado a nivel del "derecho abstracto" (BARATTA, 2000) con lo que efectivamente ocurre al nivel del "derecho en movimiento" (SUTHERLAND, 1947) o al nivel de las prácticas de selectividad secundaria (FOUCAULT, 2002; BARATTA, 2000).

Para ello trabajaremos con los últimos datos del Sistema Nacional de Estadísticas sobre Ejecución de la Pena (SNEEP), la estadística penitenciaria del país ${ }^{18}$. Es preciso hacer aquí dos aclaraciones. En primer lugar, dado que se trata de un censo sobre la población penitenciaria de la República Argentina, no analizaremos solo las condenas establecidas por los jueces en el año 2018, sino las condenas de las personas en prisión al momento del censo ${ }^{19}$. En segundo lugar, la información disponible no especifica el tipo de homicidio o de robo cometido, por lo que los resultados se ajustarán a esta distinción más general. Como sostendría Boslaugh (2007, p. 4), "uno puede trabajar con los datos que existen, no con los datos que a uno le hubieran gustado recolectar". Asimismo, cabe señalar que, si bien existen múltiples delitos codificados como atentados a la propiedad, hemos escogido trabajar con el robo por su significancia estadística (es decir, es la conducta delictiva con mayor nivel de ocurrencia) y porque creemos que es el tipo de delito que nos permitirá captar con mayor claridad las valoraciones diferenciales establecidas entre vida individual y propiedad en las prácticas efectivas del sistema penal. Por último, cabe mencionar que para llevar a cabo una comparación entre las condenas por robo y por homicidio consideraremos únicamente los casos de robo donde no haya habido muertes ni intencionales ni no intencionales.

\section{Sobre las medias de las condenas}

Un análisis sobre las medias, modas y medianas de las condenas por los delitos de homicidio doloso y robo sugiere, de una forma que pareciera irrefutable, que los homicidios dolosos son castigados de manera más severa que los robos. Entre los primeros, el promedio se ubica en los 12,3 años de prisión - o en los 16,6 años si consideramos también la población con condenas perpetuas $-y$, entre los segundos, en los 6,7 años. Esta diferencia de seis años mostraría, sin más, que, en la estructura de valores del sistema penal, la vida ocupa un lugar superior respecto de la 
propiedad privada. Sin embargo, si bien el promedio es una medida resumen muy útil, lo cierto es que, por ser muy sensible a los valores extremos de un conjunto, muchas veces puede no ser del todo representativa de la totalidad de los casos. Y esto ya que la abstracción de los datos específicos a través de esta medida resumen puede ocultar matices relevantes para el problema que aquí nos ocupa. Una comparación de los coeficientes de variación de cada grupo de condenas permite confirmar lo anterior: entre las condenas por robo se ve una mayor dispersión de los casos respecto de la media (siete años) que entre las condenas por homicidio doloso. Pero veamos todo lo anterior con mayor detalle.

El último censo penitenciario de Argentina muestra que hay 12,419 detenidos por el delito de homicidio doloso, entre los cuales un $62 \%$ tiene una condena establecida. Entre los 7,721 condenados, vemos que 1,327 , un $17 \%$, tienen penas perpetuas. Si atendemos al promedio de los montos de castigo, vemos que este se ubica en los 16,6 años al considerar la población total condenada por homicidio doloso. Ahora bien, dado que el promedio es una medida ciertamente muy sensible a los valores máximos, este 17\% de condenas fijadas en los 35 años de reclusión o más (las perpetuas) podría estar impidiendo, en parte, tener una visión general sobre el monto del castigo del resto de las condenas, que son de hecho la mayoría. Entonces, si volvemos a considerar la media en las penas por este delito, pero ahora incluyendo solo las condenas no perpetuas, observamos que esta pasa a ubicarse en los 12,3 años reclusión. De modo que, entre el $83 \%$ de los condenados por homicidio doloso, el promedio de años de castigo es ciertamente más cercano al mínimo en la escala penal del código que al máximo.

Consideremos ahora los casos de las condenas por robo o tentativa de robo en las que no ha habido muerte alguna, pero tampoco tentativas de homicidio, lesiones dolosas o culposas, violaciones, privaciones a la libertad $\mathrm{u}$ otros delitos contra las personas. Se trata de 17326 condenas, aproximadamente la mitad de la cantidad total de detenidos por este delito. Entre todas ellas es posible observar que el promedio en el monto del castigo establecido se ubica en los siete años de reclusión, promedio que es indudablemente menor al que observábamos en el caso de los homicidios dolosos. Estas diferencias entre las penas por homicidio y por robo - diferencias que son aún más notorias al incluir los castigos perpetuos - se verifican no solo en relación a las medias, sino también si comparamos la moda (valor más repetido en la población) y la mediana en cada caso. Entre las condenas por homicidio doloso, excluyendo las condenas perpetuas - esto es, considerando el 82\% de los condenados -, el valor más repetido es 12 años, mientras que este valor es cinco años para las condenas por robo. La mediana en el primer caso es de 11 años, es decir que el 50\% de los condenados por homicidio doloso fue castigado con menos de 11 años de prisión. Por su parte, si consideramos los condenados por robo, vemos que el 50\% de las penas son inferiores a los 5,5 años. 
Gráfico 1: Promedio de las condenas por homicidio doloso y robo para la población penitenciaria argentina total (en años)

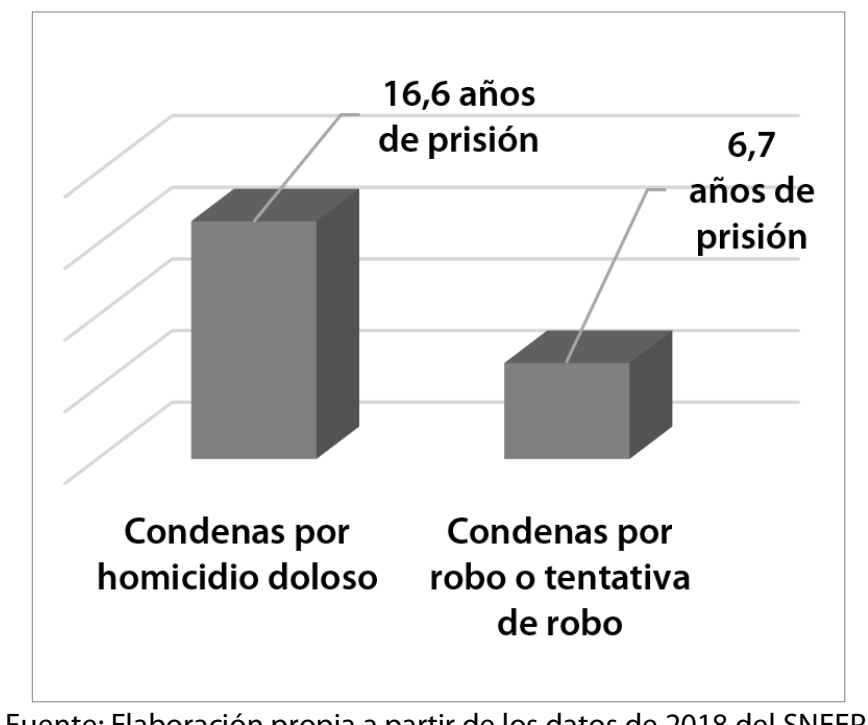

Fuente: Elaboración propia a partir de los datos de 2018 del SNEEP.

Gráfico 2: Promedio de las condenas por homicidio doloso y robo para la población penitenciaria argentina sin penas perpetuas (en años)

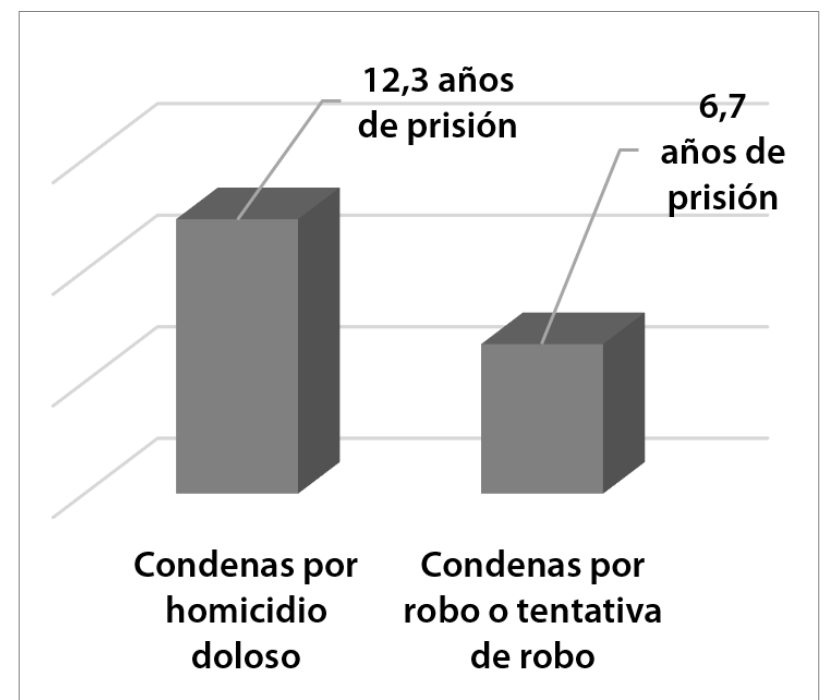

Fuente: Elaboración propia a partir de los datos de 2018 del SNEEP.

Sin embargo, como mencionábamos antes, el promedio es una medida muy sensible a los valores extremos, puesto que estos lo hacen variar notablemente provocando que pueda no ser completamente representativa de la totalidad de los casos. Es por eso que hemos insistido, para el caso del homicidio, sobre la necesidad de también dar cuenta de la media en las condenas excluyendo las penas perpetuas. En este sentido, como veíamos, el promedio de 12,3 años de reclusión es ciertamente más representativo de la totalidad de la población condenada por este delito que los 16,6 años (promedio si no se excluyen las penas perpetuas). Esta misma cuestión se nos plantea en relación a los castigos establecidos por robo. ¿Cómo saber si esos 
siete años de prisión son efectivamente representativos del total de las condenas por este delito? Una comparación entre la desviación estándar de ambas poblaciones contribuye a despejar este interrogante.

El coeficiente de variación para la población condenada por homicidio doloso es de 0,61 si se consideran todos los condenados, y de 0,40 al excluir a quienes poseen penas perpetuas. Nuevamente, esto muestra que hay un desvío mayor respecto de la media cuando se considera la totalidad de las condenas que cuando solo se toman en cuenta las penas no perpetuas. Dicho en otros términos: la media de 12,3 años es más representativa de las condenas no perpetuas por homicidio doloso que los 16,6 años respecto de la población total condenada por este delito. Comparemos ahora con las condenas por robo. Para estas últimas, el coeficiente de variación se ubica en 0,71 , lo cual señala que existe todavía un mayor desvío respecto de la media. Es decir, una mayor dispersión de los casos respecto de su promedio de siete años. Así, la media de 12,3 años de reclusión por homicidio doloso es más representativa de la mayoría de las condenas por ese delito que el promedio de siete años respecto de la totalidad de las condenas por robo.

Lo anterior hace visible que la comparación de promedios, medianas y modas no es suficiente para dar cuenta de las prácticas de castigo efectivas pues puede invisibilizar ciertas especificidades que podrían ser verdaderamente fundamentales. $\mathrm{Y}$, en tal sentido, hemos de poner momentáneamente en suspenso la afirmación según la cual los homicidios son en todos los casos más severamente castigados que los robos, algo que parecía verse con aparente claridad en un comienzo. Se vuelve preciso, entonces, ahondar un poco más en la comparación entre los castigos ejecutados para estos dos delitos a fin de poder analizar algunos matices que comportan gran relevancia para el problema que aquí estamos tratando.

\section{Las condenas según intervalos temporales}

Segmentar las poblaciones de los condenados por cada delito según intervalos temporales de castigo puede resultar de utilidad si lo que se pretende es captar las especificidades que las medidas resumen con las que antes trabajamos invisibilizan en cierta forma. Si tomamos, entonces, tres intervalos temporales - condenas de hasta 10 años de prisión; condenas de 11 a 20 años de prisión; condenas que superan los 20 años de prisión —, algunos datos interesantes salen a la luz. En primer lugar, observamos que, entre las condenas por homicidio doloso, el porcentaje de castigos superiores a los 20 años es notablemente mayor que entre las condenas por robo. Esto se encuentra en línea con lo que veíamos antes al analizar promedios, medianas y medias. No obstante, al analizar penas de menor duración, se advierte que un porcentaje significativo de homicidios dolosos ha sido castigado como la mayor parte de los robos. Asimismo, es posible 
observar que una proporción de robos ha recibido castigos superiores a una importante cantidad de homicidios ${ }^{20}$. Miremos entonces con mayor detenimiento cada intervalo temporal.

Entre los condenados por robo, un $87 \%$ recibió penas menores a los 10 años, mientras que, entre el total de los condenados por homicidio doloso, este porcentaje es de $32 \%$. Es decir que hay un $32 \%$ de homicidios dolosos que fueron castigados con penas similares a la mayoría de los robos. Sin duda, sería posible argumentar que esto podría no significar mucho pues los casos de cada uno de los delitos podrían estar agrupados en sectores opuestos del intervalo (las condenas por robo más cercanas al mínimo, y las condenas por homicidio hacia el máximo), algo que naturalmente el intervalo no deja ver. Sin embargo, si observamos este intervalo en detalle, advertimos que un $25 \%$ de las condenas por robo o tentativa de robo superan los siete años, y que en el caso de las condenas por homicidio ese porcentaje es de 69\%. Esto indica que efectivamente hay una cantidad significativa de condenas por robo de extensión similar a las establecidas por homicidio doloso: entre las penas que no superan los 10 años de prisión, más de la mitad de los homicidios se han castigado como el $25 \%$ de los condenados por robo. $\mathrm{Y}$, por lo mismo, un $31 \%$ de los homicidios (dentro de este intervalo) fueron penados como el $75 \%$ de los robos, es decir, con hasta 7 años de reclusión.

Observemos qué ocurre en el caso de las penas que se ubican entre los 11 y los 20 años de reclusión. Estas representan casi un $11 \%$ en el caso del total de los condenados por robo o tentativa de robo, y un $42 \%$ entre los condenados por homicidio doloso. La misma objeción que realizamos para el intervalo anterior podría también hacerse para este. No obstante, si miramos a su interior, vemos que el promedio en el monto de las penas ubicadas en este intervalo es de 14 años tanto para los condenados por robo como por homicidio. Vemos, asimismo, que la distribución de estos castigos es similar para ambos grupos. De esta manera, ese $11 \%$ de la población total condenada por robo tiene efectivamente penas muy similares al $42 \%$ de los condenados por homicidio doloso, y superiores al 32\% que ubicamos en el primero de los intervalos temporales mencionados (hasta 10 años de prisión).

Si ahora tomamos las penas que superan los 20 años de reclusión, vemos que, mientras que entre los condenados por homicidio estas representan un 26\% (cabe recordar que hay un $18 \%$ de la población total condenada por este delito que posee penas perpetuas), en el caso de los condenados por robo representan solo un 2\%. A diferencia de lo que podíamos ver anteriormente, aquí sí se observa que los homicidios han sido castigados en mucha mayor medida que los robos con penas superiores a 20 años de reclusión. 
Tabla 1: Monto de la condena (en años) por tipo de delito (homicidio o robo) — Población penitenciaria argentina total (2018)

\begin{tabular}{|c|c|c|}
\hline & Condenas por homicidio doloso & $\begin{array}{c}\text { Condenas por robo o } \\
\text { tentativa de robo }\end{array}$ \\
\hline Castigos de hasta 10 años de prisión & $32 \%$ & $87 \%$ \\
\hline $\begin{array}{c}\text { Castigos de entre } \mathbf{1 1} \text { y } \mathbf{2 0} \text { años de } \\
\text { prisión }\end{array}$ & $42 \%$ & $11 \%$ \\
\hline $\begin{array}{c}\text { Castigos superiores a } \mathbf{2 0} \text { años de } \\
\text { prisión }\end{array}$ & $26 \%$ & $2 \%$ \\
\hline & $\begin{array}{c}\mathbf{1 0 0 \%} \\
\mathbf{N}=\mathbf{7 7 2 1}\end{array}$ & $\begin{array}{c}\mathbf{1 0 0 \%} \\
\mathbf{N}=\mathbf{1 7 3 2 6}\end{array}$ \\
\hline
\end{tabular}

Fuente: Elaboración propia a partir de los datos de 2018 del SNEEP.

Gráfico 3: Condenas por homicidio doloso según intervalos de castigo (en años) — Población penitenciaria argentina total (2018)

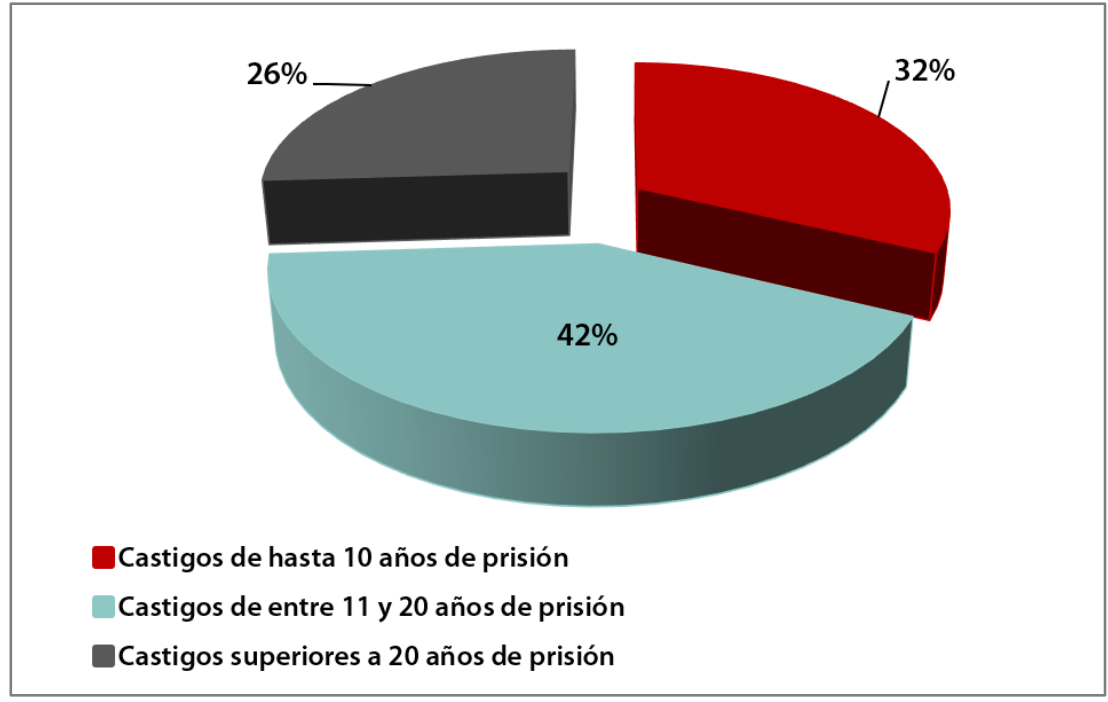

Fuente: Elaboración propia a partir de los datos de 2018 del SNEEP.

Gráfico 4: Condenas por robo o tentativa de robo según intervalos de castigo (en años) — Población penitenciaria argentina total (2018)

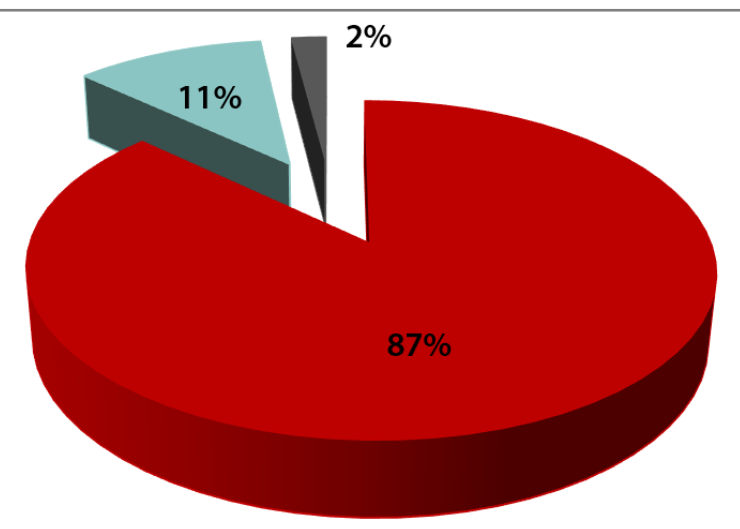

Castigos de hasta 10 años de prisión

Castigos de entre 11 y 20 años de prisión

Castigos superiores a 20 años de prisión

Fuente: Elaboración propia a partir de los datos de 2018 del SNEEP. 
Lo anterior muestra que una mirada más cuidadosa sobre los montos de los castigos nos obliga necesariamente a matizar la afirmación según la cual el sistema penal rechaza con mayor intensidad las conductas que atentan contra la vida que las que atentan contra la propiedad privada, afirmación que parece emerger con claridad a partir del análisis de las medidas resumen presentadas. Es que, si bien entre las condenas por homicidio el porcentaje de castigos que superan los 20 años es notablemente mayor que entre las condenas por robo, es en las penas menos severas donde tales matices se hacen visibles. Si vimos que la mayoría de las condenas por robo son inferiores a los 10 años de prisión y que, entre las condenas por homicidio doloso, este porcentaje es ciertamente significativo (32\%) también, ¿̇podemos continuar afirmando sin más que el sistema penal defiende más el valor de la vida que el valor de la propiedad privada? ¿Cómo explicar entonces que la administración de justicia esté castigando atentados a la vida y a la propiedad con igual severidad? Asimismo, ¿qué decir acerca de que una cierta cantidad de robos hayan sido penalizados con penas más elevadas que una parte de los homicidios? ¿Qué señalan estas prácticas sobre la relación entre la vida y la propiedad privada en la estructura de valores del sistema penal?

\section{A modo de cierre}

A lo largo de nuestro trabajo hemos intentado explorar el modo en que el sistema penal argentino configura la relación y las jerarquías entre dos valores hegemónicos en nuestras sociedades: la vida individual y la propiedad privada. La primera conclusión que se desprende del análisis sobre la codificación y las prácticas de castigo vigentes es que se trata de dos valores altamente resguardados por el sistema penal argentino. Mediante el castigo del asesinato y de los atentados a la propiedad, el sistema penal se orienta hacia una fuerte defensa de estos valores ideológicos primeros. O, como sostendría Frondizi (2010), los define como valores superiores.

Pero este trabajo nos ha permitido fundamentalmente problematizar y poner en cuestión la aserción generalizada de que la vida individual es el valor más protegido y el asesinato el peor de los crímenes. $\mathrm{O}$, dicho de otro modo, nos ha permitido ver que en estas prácticas penales la vida individual no es tan valiosa como el imaginario colectivo tiende a suponer. El análisis de la penalización diferencial del asesinato y del robo ha puesto de manifiesto que hay muertes infligidas intencionalmente para las que se establecen penas más leves que para ciertos atentados a la propiedad. Es el caso, por ejemplo, del homicidio en riña y del robo con arma: mientras que para el primero la escala penal es de dos a seis años, para el segundo va de 11 a 16 años de prisión. Esto también puede verse para otros homicidios cuando no se utilice un arma de fuego. En línea con ello, el análisis de las penas impuestas ha mostrado que una proporción no menor (32\%) de 
los asesinatos ha sido castigada como la mayoría de los robos - con menos de 10 años de prisión. $\mathrm{Y}$, de igual modo, vimos que existe un porcentaje significativo de condenas por robo semejantes a la mayor parte de las penas por asesinato - entre 11 y 20 años de prisión -, y superiores al conjunto de los homicidios penados con menos de 10 años de prisión.

La importancia que la propiedad privada como valor reviste para el sistema penal, algo que habitualmente tiene poca visibilidad social, también se ve claramente en la severidad con la que este responde a las acciones que combinan el ataque a la propiedad y a la vida individual. Vimos que los atentados a la propiedad agravan colosalmente los atentados a la vida. Y los agravan tanto como los vínculos de parentesco, por ejemplo. Es decir, es tan grave asesinar a un hijo como asesinar a alguien para robarle. Lo anterior sugiere, entonces, que la relación que el sistema penal argentino estructura entre vida individual y propiedad privada es una relación muy peculiar en donde la supremacía de la primera por sobre la segunda ya no puede ser afirmada de manera absoluta y sin matices. Ya no es posible sostener de forma taxativa que la vida individual está más resguardada que la propiedad privada. Se puede más bien observar que, respecto de determinadas muertes, ocurre precisamente lo contrario.

Además de esto, es importante señalar que, en la práctica penal efectiva también intervienen otras variables, extrajurídicas, que por las características de este trabajo no han podido ser abordadas. Nos referimos, por ejemplo, a la edad, la nacionalidad, y la clase social tanto de los imputados como de las víctimas, todos ellos criterios muy analizados en numerosas investigaciones que han explorado el carácter selectivo de todas las instancias del sistema penal en la región (RIBEIRO, 2010; MISSE, 2011; RODRÍGUEZ, 2012; EILBAUM y MEDEIROS, 2015; LERCHUNDI y BONVILLANI, 2018; VEGH WEIS, 2019; ROUTIER, 2020; LASSALLE, 2018, 2020). Y, de igual modo, intervienen actores extrajurídicos y acontecimientos sociohistóricos que, como han mostrado Kessler y Gayol (2018), transforman ciertas muertes en problemas públicos y en "muertes que importan".

Finalmente, luego de haber visibilizado que la supremacía absoluta del valor de la vida individual por sobre el de la propiedad privada, que el imaginario colectivo tiende a suponer, no es tal en el seno de estas prácticas penales, creemos que este trabajo también contribuye a abrir nuevos interrogantes para futuras investigaciones. Como hemos señalado, las prácticas de penalización son siempre diferenciales: los atentados a la propiedad y los homicidios no son criminales todos en igual medida y de ahí que las escalas penales sean amplias tanto en uno como en otro caso. Estas muestran, por tanto, que nunca se castiga la muerte o el robo en general, y que la vida individual y la propiedad privada no aparecen como abstractas en estas prácticas. Y esto porque siempre hay otros sentidos sociales en juego, sentidos que, en nuestra hipótesis, responden a la estructura ideológica y a las relaciones desiguales de propiedad, género y poder vigentes que 
el propio sistema penal contribuye a reproducir. Además, y por lo mismo, estas diferenciaciones y selectividades producen, y comunican socialmente, qué acciones serán vistas como los atentados a la vida y a la propiedad paradigmáticos o típicos, y cuáles permanecerán fuera de la visibilidad social. En este sentido, podemos decir que las penas establecidas por este código, y los castigos efectivamente impuestos, contribuyen a producir y fijar el vínculo estrecho que existe, por ejemplo, entre el robo y el asesinato en el imaginario colectivo contemporáneo - basta mirar las noticias o los resultados de encuestas sobre percepción de inseguridad para observar este vínculo. De manera que, para poder avanzar en la elaboración de un mapa exhaustivo de las jerarquizaciones que el sistema penal argentino produce en torno al valor de la vida y la propiedad privada, estos sentidos colectivos, también en juego, no pueden ser desatendidos. Este trabajo intenta ser un primer paso en esa dirección.

\section{Notas}

1 Quiero agradecer a los compañeros y compañeras del Grupo de Estudios sobre Estructuralismo y Postestructuralismo
del Instituto de Investigaciones Gino Germani por la lectura del texto y por sus valiosos comentarios. Un agradecimiento
también a los evaluadores de este artículo, cuyas sugerencias fueron muy enriquecedoras.

${ }^{2}$ Si bien no podremos externos en este punto aquí, basta con mencionar que, según Bourdieu (2010), la eficacia simbólica del derecho - donde la codificación ocupa un lugar fundamental - está vinculada al efecto de universalización que produce. La institución jurídica contribuye a imponer universalmente una representación de la normalidad en relación a la cual todas las prácticas diferentes tienden a aparecer como desviadas, anómicas, anormales.

${ }^{3}$ En este artículo nos referiremos al sistema penal argentino, incluyendo en esta categoría al poder legislativo en tanto que productor de leyes penales y a la justicia penal. Entendemos, sin embargo, que nuestro trabajo excluye un análisis directo sobre otras instancias fundamentales de este dispositivo, como la policía y el servicio penitenciario.

${ }^{4}$ Elegimos hablar de valores y no de bienes jurídicos - como lo hace el discurso del derecho - pues creemos que la noción de "bien" da cuenta de una entidad cerrada con valor en sí misma. En contraste con ello, pensar en valores nos obliga a considerar, en primer lugar, el carácter necesariamente relacional que comportan (FRONDIZI, 2010; BOURDIEU, 1973 , 2015). Así, la vida, pero también la propiedad o cualquier otro valor, ya no podrán ser pensados con independencia de sus vínculos con el resto. Pero, asimismo, la noción de valor ideológico nos permite señalar que se trata de valores y sentidos que están siempre en disputa y que esa disputa es siempre una disputa política, aun en el ámbito del derecho.

${ }^{5}$ Cabe aclarar que, en Argentina, la prisión perpetua no implica confinamiento de por vida, sino la imposibilidad de solicitar la libertad condicional hasta cumplidos los 35 años de encierro. En el caso de las penas no perpetuas, la libertad condicional puede ser solicitada - aunque no para todos los delitos - luego de cumplidos los $2 / 3$ de la condena (siempre que el condenado cumpla una serie de requisitos).

${ }^{6}$ Esto también era válido para el aborto (codificado como atentado a la vida) antes de la aprobación de la Ley de Acceso a la Interrupción Legal del Embarazo (ley no 26.610) en Argentina en diciembre de 2020. Según esta nueva ley, no es delito el aborto realizado con consentimiento de la persona gestante hasta la semana 14 inclusive del proceso gestacional. A su vez, esta ley estipula penas mucho menores (de entre un mes y tres años) a las anteriores para quien causar su propio aborto luego de ese plazo. Si bien no ahondaremos sobre esto, la sanción de esta ley muestra con claridad una de las cuestiones centrales que intentamos señalar en este trabajo; a saber, que los procesos de codificación entrañan una disputa política por la penalización - o des-penalización, en este caso - de determinadas prácticas, y por la reafirmación de ciertos valores colectivos y no de otros. Y estas disputas exceden por mucho al campo jurídico. En el caso de esta ley, el rol que tuvieron los reclamos y luchas del movimiento de mujeres en su heterogeneidad es fundamental. Esto a su vez se vio reforzado porque otros actores extrajurídicos, como ciertos medios de comunicación y organizaciones sociales, contribuyeron a propagar una serie de creencias colectivas sobre la mujer, su cuerpo, las posibilidades de elegir la maternidad etc., que cuestionaron fuertemente aquellas que han hegemonizado nuestras sociedades patriarcales durante muchos años.

${ }^{7}$ Cabe señalar que el femicidio no constituye un tipo penal por fuera del homicidio, sino que, a partir de la incorporación de este inciso en el artículo 80 del código penal, funciona como un agravante específico del mismo. 
${ }^{8}$ Cabe remarcar aquí que, más allá de que exista intención o no, se trata de homicidios en los que no se puede establecer un nexo causal entre el robo y la muerte ocasionada. Los homicidios en los que los jueces sí identifican este nexo, es decir, los homicidios que hayan sido perpetrados para poder consumar, facilitar u ocultar un robo, son codificados como criminis causae - y penados con aun mayor severidad, tal como veíamos más arriba. Señalemos, sin embargo, que, en nuestra hipótesis, la identificación de este "nexo causal" en la práctica penal efectiva responde menos a un problema doctrinario o "de prueba" que a sentidos y valores hegemónicos, y a las relaciones desiguales de género, poder y propiedad, que atraviesan y son reproducidas por el sistema penal.

${ }^{9}$ Al hablar de homicidio en riña, nos referimos a aquellos homicidios cometidos por dos o más personas, en donde no se puede determinar quién causó la muerte. En este caso, todas las personas que participaron serían responsables por el hecho. Por su parte, cuando un homicidio es definido como preterintencional se entiende que la persona quería causar daño sobre la víctima, pero que los medios utilizados no deberían haberle causado la muerte. Finalmente, por su parte, el homicidio bajo emoción violenta es un homicidio cometido por alguien que, en un estado de perturbación de la conciencia, no podía comprender claramente lo que estaba haciendo. Mencionemos en este punto que todas estas calificaciones se estrategizan en las prácticas penales en función de lógicas y conflictos de intereses propios del campo jurídico, así como también en función de los sentidos sociales hegemónicos y de las relaciones desiguales de género, poder y propiedad que los atraviesan. De este modo, por ejemplo, en nuestras sociedades patriarcales, la figura de la emoción violenta fue históricamente muy utilizada para atenuar las penas de los hombres que asesinaban a sus esposas por celos. Cf. Rodríguez y Chejter (2014).

${ }^{10}$ Se trata del homicidio que no posee los agravantes explicitados en el artículo 80 del código penal (que mencionamos anteriormente), y para el cual no se prescriben penas perpetuas.

11 Código Penal Argentino, artículo 34, inciso 6. Disponible (on-line) en: http://servicios.infoleg.gob.ar/infolegInternet/anexos/15000-19999/16546/texact.htm

${ }^{12}$ Para un análisis sobre el uso de esta figura jurídica, ver Lassalle (2021).

${ }^{13}$ Aquí, se incluyen, por ejemplo, el hurto de maquinarias o de instrumentos de trabajo, y el hurto cometido en medio de un incendio, accidente o explosión.

${ }^{14}$ La diferencia fundamental entre hurto y robo es que en el hurto no hay uso de la fuerza sobre las cosas ni sobre las personas, ni tampoco intimidación de estas últimas.

${ }^{15}$ Cabe aclarar que, si el arma fuese de juguete o no se pudiera comprobar su aptitud para el disparo, las penas van de tres a 10 años de prisión.

${ }^{16}$ Para una profundización sobre este tema, se recomienda ver Manchado (2012), Murillo, (2008) y Martínez (2005).

${ }_{17}$ Para un análisis de cada una de las leyes, se sugiere ver Olaeta y Ciafardini (2020) y Calzado y Van Der Dooren (2016).

${ }^{18}$ Censo correspondiente a diciembre de 2018. Estos datos son de acceso abierto. Disponible (on-line) en: https://www2.jus.gov.ar/dnpc/sneep.html

${ }^{19}$ Esto naturalmente incluye condenas de años anteriores. Cabe señalar que los primeros datos censales disponibles corresponden al año 2002.

${ }^{20}$ Podría argumentarse que lo que en realidad explica esto es la variable "reincidencia del condenado". Y esto podría sostenerse además, puesto que entre quienes comenten robos los porcentajes de reincidencia son más altos que entre quienes cometen homicidios - entre los primeros hay un $35 \%$ de reincidentes, y entre los segundos un $25 \%$. No obstante, los datos analizados muestran que el promedio de las penas para ambos grupos de condenados solo varía 0,3 años si excluimos a quienes son reincidentes. 


\section{Referencias}

BARATTA, Alessandro. Criminología crítica y crítica del derecho penal. México: Siglo XXI, 2000.

BECKER, Howard. "Iniciativas morales”. In: BECKER, Howard. Outsiders: Hacia una sociología de la desviación. Buenos Aires: Siglo XXI, 2012.

BERGALLI, Roberto. "Control social y sistema penal". In: BERGALLI, Roberto et al. Control social punitivo: Sistema penal e instancias de aplicación (Policía, Jurisdicción y Cárcel). Barcelona: María Jesús, 1996.

BOSLAUGH, Sarah. Secondary Data Sources for Public Health. Cambridge: Cambridge University Press, 2007.

BOURDIEU, Pierre. "Condición de clase y posición de clase". In: SAZBÓN, José. Estructuralismo y sociología. Buenos Aires: Nueva Visión, 1973.

BOURDIEU, Pierre. "La fuerza del derecho: Elementos para una sociología del campo jurídico". In: BOURDIEU, Pierre. Poder, derecho y clases sociales. Bilbao: Desclée, 2010.

BOURDIEU, Pierre. El sentido práctico. Buenos Aires: Siglo XXI, 2015.

CALZADO, Mercedes; VAN DEN DOOREN, Sebastián. “¿Leyes Blumberg? Reclamos sociales de seguridad y reformas penales". Delito y Sociedad, vol. 1, n. 27, pp. 97-113, 2016.

CARNELUTTI, Francesco. Cómo se hace un proceso. Cidade do México: Colofón, 2016.

EILBAUM, Lucía; MEDEIROS, Flavia. "Quando existe 'violência policial'? Direitos, moralidades e ordem pública no Rio de Janeiro”. Dilemas, Rev. Estud. Conflito Controle Soc., Rio de Janeiro, vol. 8, n. 3, pp. 407-428, 2015.

FOUCAULT, Michel. Vigilar y castigar: Nacimiento de la prisión. Buenos Aires: Siglo XXI, 2002.

FRONDIZI, Risieri. ¿Qué son los valores? Introducción a la axiología. Cidade do México: Fondo de Cultura Económica, 2010.

GARLAND, David. Castigo y sociedad moderna: Un estudio de teoría social. Cidade do México: Siglo XXI, 1999.

KESSLER, Gabriel; GAYOL, Sandra. Muertes que importan: Una mirada sociohistórica sobre los casos que marcaron la Argentina reciente. Buenos Aires: Siglo XXI, 2018.

LASSALLE, Martina. "Sobre el castigo del homicidio doloso en la Argentina contemporánea". Revista Pilquen - Sección Ciencias Sociales, vol. 21, n. 2, pp. 95-108, 2018.

LASSALLE, Martina. "Differential Penalization of Murder: An Examination of the Argentinean Case”. Espacio Abierto, vol. 29, n. 3, pp. 184-200, 2020.

LASSALLE, Martina. "Non-Criminal Murders: A Sociological Essay about the Penal Use of SelfDefence in Argentina”. Oñati Socio-Legal Series, 2021 (no prelo).

LERCHUNDI, Mariana; BONVILLANI, Andrea. "Narrativas racistas y criterios de selectividad policial. Experiencias de violentación policial de jóvenes de sectores populares (Río Cuarto, Argentina)". Encrucijadas: Revista Crítica de Ciencias Sociales, vol. 16, pp. 1-21, 2018. 
MANCHADO, Mauricio. "Sujetos estigmatizados y discursividad en torno a la noción de individuo peligroso en las declaraciones mediáticas de Juan Carlos Blumberg”. In: ALVAREZ, Graciela et al. Norma y transgresión: El imperativo de la ley y las prácticas sociales. Rosario: Fundación para el desarrollo de la Ciencia Jurídica, 2012.

MARTÍNEZ, Fabiana. "Pánicos sociales, ciudadanía episódica y exclusión: Análisis del caso Blumberg en medio gráficos argentinos”. Signo y Pensamiento, vol. 24, n. 46, pp. 125-136, 2005.

MISSE, Michel. Malandros, marginais e vagabundos e a acumulação social da violência no Rio de Janeiro. Tese (Doutorado em Sociologia) - Instituto Universitário de Pesquisas do Rio de Janeiro, Rio de Janeiro, 1999.

MISSE, Michel. "Crime, sujeito e sujeição criminal: Aspectos de uma contribuição analítica sobre a categoria 'bandido”'. Lua Nova, vol. 79, pp. 15-38, 2010.

MISSE, Michel. "O papel do inquérito policial no processo de incriminação no Brasil: Algumas reflexões a partir de uma pesquisa”. Sociedade e Estado, vol. 26, n. 1, pp. 15-27, 2011.

MURILLO, Susana. "Juan Carlos Blumberg y la interpelación de la sociedad civil". In: MURILLO, Susana. Colonizar el dolor. La interpelación ideológica del Banco Mundial en América Latina. El caso argentino desde Blumberg a Cromañón. Buenos Aires: Clacso, 2008, pp. 171-213.

OLAETA, Hernán; CIAFARDINI, Mariano. Punitivismo en Argentina: Un abordaje del sistema penal (2000-2016). Buenos Aires: Sb Editorial, 2020.

PAVARINI, Massimo. Control y dominación: Teorías criminológicas burguesas y proyecto hegemónico. Buenos Aires: Siglo XXI, 2003.

RIBEIRO, Ludmila. "A produção decisória do sistema de justiça criminal para o crime de homicídio: Análise dos dados do estado de São Paulo entre 1991 e 1998”. Dados: Revista de Ciências Sociais, vol. 53, n. 1, pp. 159-193, 2010.

RODRÍGUEZ, Esteban. "Circuitos carcelarios: El encarcelamiento masivo-selectivo, preventivo y rotativo en la Argentina". Questión: Revista especializada en periodismo y comunicación, vol. 36, n. 1, pp. 81-96, 2012.

RODRÍGUEZ, Marcela; CHEJTER, Silvia. Homicidios conyugales y de otras parejas: La decisión judicial y el sexismo. Buenos Aires: Editores del Puerto, 2014.

ROUTIER, María Eva. "Experiencias de desigualdad. Trayectorias de detención, condiciones de encierro y selectividad intramuros en el acceso a la educación secundaria de jóvenes y adultos privados de su libertad en Santa Fe, Argentina". Revista Latinoamericana De Estudios Educativos, vol. 50, n. 1, pp. 77-102, 2020.

SUTHERLAND, Edwin. Principles of Criminology. Chicago: J.B. Lippincott Co, 1947.

TONKONOFF, Sergio. La oscuridad y los espejos: Ensayos sobre la cuestión criminal. Buenos Aires: Pluriverso, 2019a.

TONKONOFF, Sergio. “¿Qué son las Prohibiciones fundamentales? Un abordaje postestructuralista de la cuestión criminal”. Revista Pilquen - Sección Ciencias Sociales, vol. 22, n. 4, pp. 36-49, 2019 b. 
VEGH WEIS, Valeria. "Por una criminología crítica verde del Sur. Un análisis sobre selectividad penal, pueblos indígenas y daños ambientales en Argentina”. Revista Crítica Penal y Poder, n. 16, pp. 53-74, 2019.

RESUMEN: Este artículo examina el modo en que el sistema penal argentino estructura la relación y las jerarquías entre dos valores supremos en las sociedades contemporáneas: la vida individual y la propiedad privada. Para ello, analizamos cómo que se penalizan los asesinatos y los atentados a la propiedad privada. En primer lugar, consideraremos las penas establecidas por el código penal. Luego, dado que existe una distancia importante entre lo que el derecho codifica como prohibido y el modo efectivo en que opera la agencia judicial, analizaremos y compararemos las condenas efectivamente impuestas para los asesinatos y los robos.

Palavras-chave: vida individual, propiedad privada, asesinato, robo, sistema penal argentino
MARTINA LASSALLE (lassallemartina@gmail.com) é professora de sociologia da Facultad de Ciencias Sociales da Universidad de Buenos Aires (UBA, Argentina). É doutoranda em ciências sociais na UBA, com uma bolsa doutoral da mesma universidade, e licenciada em sociologia pela mesma instituição. Membro da equipe de investigação da Secretaria de Ciência e Técnica da UBA, chamada "Os usos sócio-políticos da violência: Para uma análise cultural da questão criminal na Argentina".

https://orcid.org/0000-0002-8022-7007 